\title{
A Simple Sample Preparation with HPLC-UV Method for Estimation of Amlodipine from Plasma: Application to Bioequivalence Study
}

\author{
S.N. Meyyanathan*, S. Muralidharan, S. Rajan, K. Gopal and B. Suresh \\ Department of Pharmaceutical Analysis, J.S.S. College of Pharmacy, Tamilnadu, India
}

\begin{abstract}
A simple, rapid and selective method was developed for the estimation of amlodipine from human plasma. The method involves a simple protein precipitation techniques using nifedipine as internal standard. Chromatographic separation was carried out on a reverse phase $\mathrm{C}_{18}$ column using mixture of $50 \mathrm{mM}$ potassium di hydrogen ortho phosphate $(\mathrm{pH}$ $7.5)$ and acetonitrile $(60: 40, \mathrm{v} / \mathrm{v})$ at a flow rate of $1.0 \mathrm{~mL} / \mathrm{min}$ with $\mathrm{UV}$ detection at $239 \mathrm{~nm}$. The retention time of amlodipine and internal standard were 4.12 and $8.31 \mathrm{~min}$, respectively. The method was validated and found to be linear in the range of $0.5-50.0 \mathrm{ng} / \mathrm{mL}$. An open, randomized, two-treatment, two period, single dose crossover, bioequivalence study in 24 fasting, healthy, male, volunteers was conducted. After dosing, serial blood samples were collected for the period of $168.0 \mathrm{~h}$. Various pharmacokinetic parameters including $\mathrm{AUC}_{0-\mathrm{t}}, \mathrm{AUC}_{0-\infty}, \mathrm{C}_{\max }, \mathrm{T}_{\max }, \mathrm{T}_{1 / 2}$, and elimination rate constant $\left(K_{\mathrm{el}}\right)$ were determined from plasma concentration of both formulations of test (Amlodipine $5 \mathrm{mg}$ tablets) and reference (Amlodipine $5 \mathrm{mg}$ tablets). Log transformed values were compared by analysis of variance (ANOVA) followed by classical 90\% confidence interval for $\mathrm{C}_{\max }, \mathrm{AUC}_{0-t}$ and $\mathrm{AUC}_{0-\infty}$ and was found to be within the range. These results indicated that the analytical method was linear, precise and accurate. Test and reference formulation were found to be bioequivalent.
\end{abstract}

\section{INTRODUCTION}

Amlodipine besylate is chemically described as 3-ethyl-5methyl( \pm )-2-[(2-aminoethoxy)methyl]-4-(2-chloro phenyl)1,4-dihydro-6-methyl-3,5-pyridine dicarboxylate mono benzene sulphonate. It is a dihydropyridine calcium channel blocker; activity resides mainly in the (-) isomer, that inhibits the transmembrane influx of calcium ions into vascular smooth muscle and cardiac muscle. The contractile processes of cardiac muscle and vascular smooth muscle are dependent upon the movement of extracellular calcium ions into these cells through specific ion channels. Only few bioanalytical methods were reported for the determination of amlodipine in biological samples [1-7]. There were no simple, rapid and reproducible methods so far reported for the estimation of amlodipine in plasma. The objective of the present investigation was to develop a new, rapid and sensitive RP-HPLC method for the estimation of amlodipine in human plasma using perchloric acid as a precipitating agent with $\mathrm{C}_{18}$ column and this method was applied to a bioequivalence study of amlodipine $5.0 \mathrm{mg}$ tablets using human volunteers. The outcome of a study depends upon the reliability, reproducibility and sensitivity of the analytical methodology employed. Therefore, the bioanalytical method was validated in accordance with USFDA guidelines prior to the initiation of the study.

\section{EXPERIMENTAL}

\section{Chemicals and Reagents}

Working standard of amlodipine besylate with $99.96 \%$ purity (German Remedies Ltd., Mumbai, India), nifedipine

*Address correspondence to this author at the Department of Pharmaceutical Analysis, J.S.S. College of Pharmacy, Tamilnadu, India; Tel: +91-4232443393; Fax: +91-423-2442937; E-mail: meyys@rediffmail.com with $99.56 \%$ purity (Cadila Health Care Ltd., Ahmedabad, India), HPLC grade acetonitrile, methanol (Qualigens Fine Chemicals, Mumbai, India), potassium dihydrogen ortho phosphate, ortho phosphoric acid, and perchloric acid (S.D. Fine Chem. Ltd., Mumbai, India) were used. In house mill Q water was used throughout the study. Fresh frozen human plasma used in the method development was obtained from the Vijay Hospital, Ooty, India and was stored at $-20{ }^{\circ} \mathrm{C}$ until required.

\section{Instrumentation and Chromatography}

The HPLC system consisted of a HPLC 2010 A HT (Shimadzu Ltd., Japan), Auto injector port with $100 \mu \mathrm{L}$ loop (Rheodyne, USA) and UV detector (Shimadzu Ltd., Japan). The wavelength of the detector was set at $239 \mathrm{~nm}$. Detector output was quantified on CLASS VP (Version 6.01) chromatography software. Separation was carried out on a Princeton SHER $\mathrm{C}_{18}, 4.6 \mu \mathrm{m} \times 250 \mathrm{~mm}$, Japan, using mixture of 50 $\mathrm{mM}$ potassium di Hydrogen ortho phosphate $(\mathrm{pH} 7.5)$ and acetonitrile $(60: 40, \mathrm{v} / \mathrm{v})$ as a mobile phase, at a flow rate of 1 $\mathrm{mL} / \mathrm{min}$. Total analysis time was $10 \mathrm{~min}$. All analysis was performed at room temperature.

\section{Preparation of Calibration Standard}

Stock solutions of amlodipine and nifedipine (I.S) (1 $\mathrm{mg} / \mathrm{ml}$ ) were dissolved in water and stored at $4^{\circ} \mathrm{C}$. The stock solution of amlodipine was further diluted with water to give series of standard solutions. Calibration standard of amlodipine $(0.50,1.0,2.5,5.0,10.0,15.0,25.0$ and $50.0 \mathrm{ng} / \mathrm{mL})$ were used by spiking appropriate amount of the standard solution in blank plasma.

\section{Quality Control Standards}

Lowest quality control standards (LQC), median quality control standards (MQC) \& highest quality control standards 
(HQC) were used by spiking drug free plasma with amlodipine to give solutions containing $1.0,10.0$ and $50.0 \mathrm{ng} / \mathrm{mL}$, respectively. They were stored at $-20^{\circ} \mathrm{C}$ till analysis.

\section{Sample Preparation}

The sample was prepared by adding $1 \mathrm{ml}$ of plasma containing amlodipine (calibration standard) into $100 \mu \mathrm{L}$ of internal standard $(10 \mu \mathrm{g} / \mathrm{mL})$ and followed by adding $100 \mu \mathrm{L}$ of $10 \%$ perchloric acid, which was vortexed followed by centrifugation at $4000 \mathrm{RFC}$ for $15 \mathrm{~min}$ at $4^{\circ} \mathrm{C}$. The supernatant solution was separated and injected. The sample chromatogram was presented in Fig. (1).

\section{Validation}

The validation parameter [8] like selectivity of the method was checked for interference from plasma. The standard curve consisting of five points ranging from 0.5 to 50.0 $\mathrm{ng} / \mathrm{mL}$ was developed. Quality control samples of LQC (1.0 $\mathrm{ng} / \mathrm{mL}), \mathrm{MQC}(10.0 \mathrm{ng} / \mathrm{mL})$ and HQC $(50.0 \mathrm{ng} / \mathrm{mL})$ were used to determine the intra and inter-day precision and accuracy of the assay. Peak area ratios of amlodipine to internal standard were fit to linear equation $(y=7 e-05 x+0.0006)$ and drug concentration in control samples along with the same day standard curve samples were calculated using this equa- tion. For all the curves the correlation coefficients $\left(r^{2}\right)$ were never lower than 0.9996 .

\section{Clinical Design}

The study protocol was approved by the Institution ethics committee. Twenty four healthy male Indian subjects with mean age group 20-30 years and average weight $65.8 \pm 6.1$ $\mathrm{kg}$ were included in the study. Subjects were excluded from the study if one or more of following criteria were present at time of medical screening: allergic to amlodipine, history or clinical data of renal or liver disease, positive test for hepatitis $\mathrm{B}, \mathrm{HIV}$, history of alcohol, drug addiction or donated blood within 72 days prior to study. Test and reference formulations of amlodipine $5.0 \mathrm{mg}$ tablet were administered with $240 \mathrm{ml}$ of water. The study was conducted as $24 \times 2$ single dose, randomized, open, and complete crossover design. Volunteers were fasted overnight before and $4 \mathrm{~h}$ after drug administration. Blood sample $(5 \mathrm{ml})$ were collected at 0.0 , $0.5,1.0,2.0,4.0,6.0,8.0,10.0,12.0,18.0,24.0,36.0,48.0,72.0$ and $168.0 \mathrm{~h}$ of post drug administration through an indwelling cannula into heparinized glass vials. After drug administration standard breakfast and lunch were provided at 4 and $6 \mathrm{~h}$ post dose. The blood samples were immediately centrifuged, plasma was separated and stored at $-20^{\circ} \mathrm{C}$ until ana-

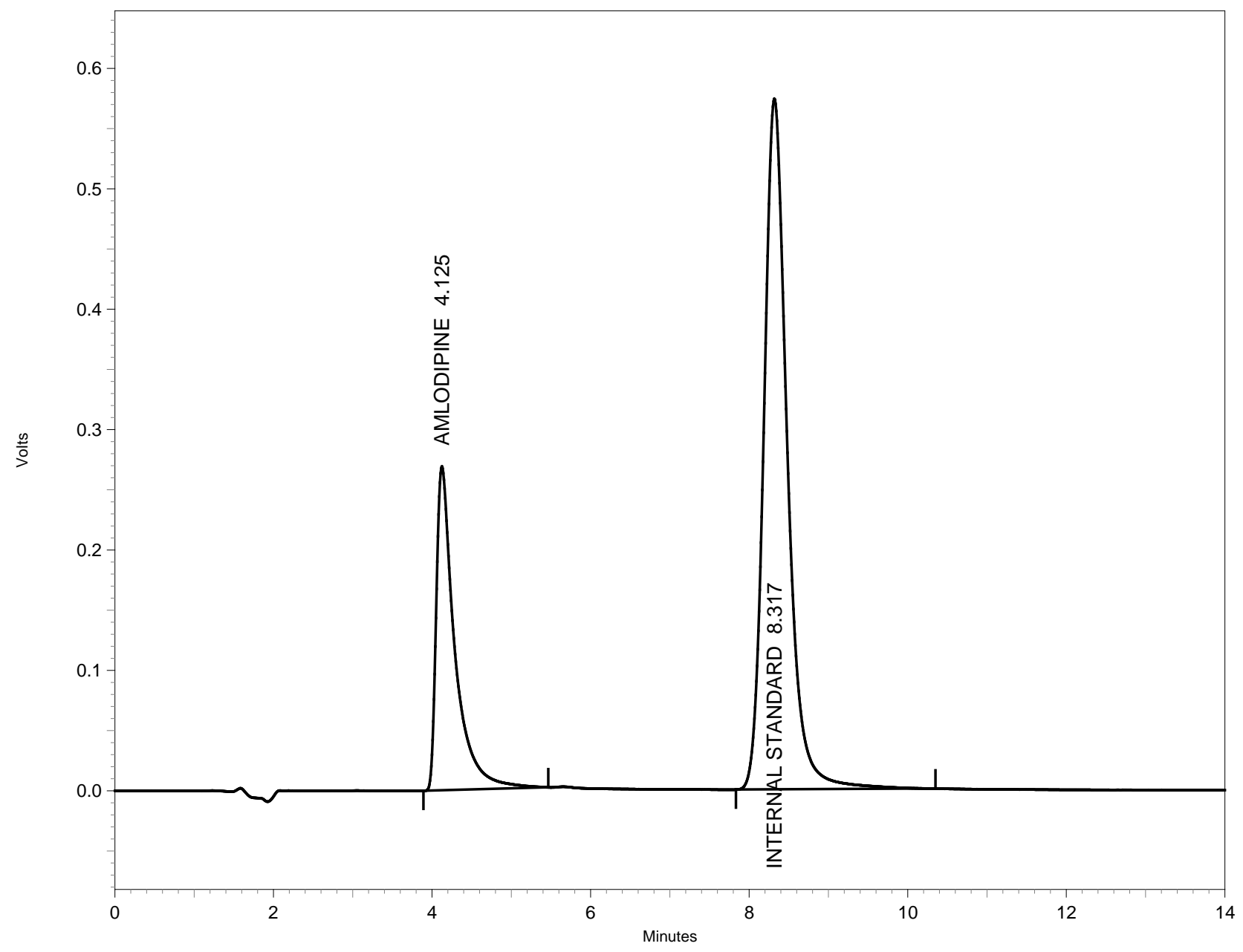

Fig. (1). Sample Chromatogram of amlodipine and internal standard. 
lyzed. After a washout period of 7 days, the study was repeated in the same manner to complete the crossover design. The plasma samples obtained at various time intervals were analzsed by the HPLC method developed.

\section{Pharmacokinetic Analysis}

The plasma concentration profile obtained was fed into PK solution, computer software on Microsoft Excel ${ }^{\circledR}$, to determine the pharmacokinetic parameters. The maximum amlodipine concentration $\mathrm{C}_{\max }$ and the corresponding peak time $\mathrm{T}_{\max }$ were determined by the inspection of the individual drug plasma concentration-time profiles. The elimination rate constant $\mathrm{K}_{\mathrm{el}}$ was obtained from the least-square fitted terminal log-linear portion of the plasma concentration-time profile. The elimination half-life $\mathrm{T}_{1 / 2}$ was calculated as $0.693 / \mathrm{K}_{\mathrm{el}}$. The area under the curve to the last measurable concentration $\left(\mathrm{AUC}_{0-t}\right)$ was calculated by the linear trapezoidal rule. The area under the curve extrapolated to infinity
$\left(\mathrm{AUC}_{0-\infty}\right)$ was calculated asAUC $\mathrm{C}_{0-t}+\mathrm{C}_{\mathrm{t}} / \mathrm{K}_{\mathrm{el}}$ where $\mathrm{C}_{\mathrm{t}}$ is the last measurable concentration.

\section{Statistical Analysis}

For the purpose of bioequivalence analysis $\mathrm{AUC}_{0-t}, \mathrm{AUC}_{0-\infty}$ and $C_{\max }$ were considered as primary variables. Bioequivalence of two formulations was assessed by means of an analysis of variance (ANOVA) for crossover design and calculating $90 \%$ confidence interval of the ratio of test/reference using $\log$ transformed data. The formulation was considered bioequivalent when the difference between two compared parameters was found statistically $[9,10]$ insignificant $(p>0.05)$ and confidence interval for these parameters fell within $80-125 \%$.

\section{RESULTS AND DISCUSSION}

\section{Selectivity}

Selectivity of the method described was investigated by screening six different batches of human blank plasma. Un-

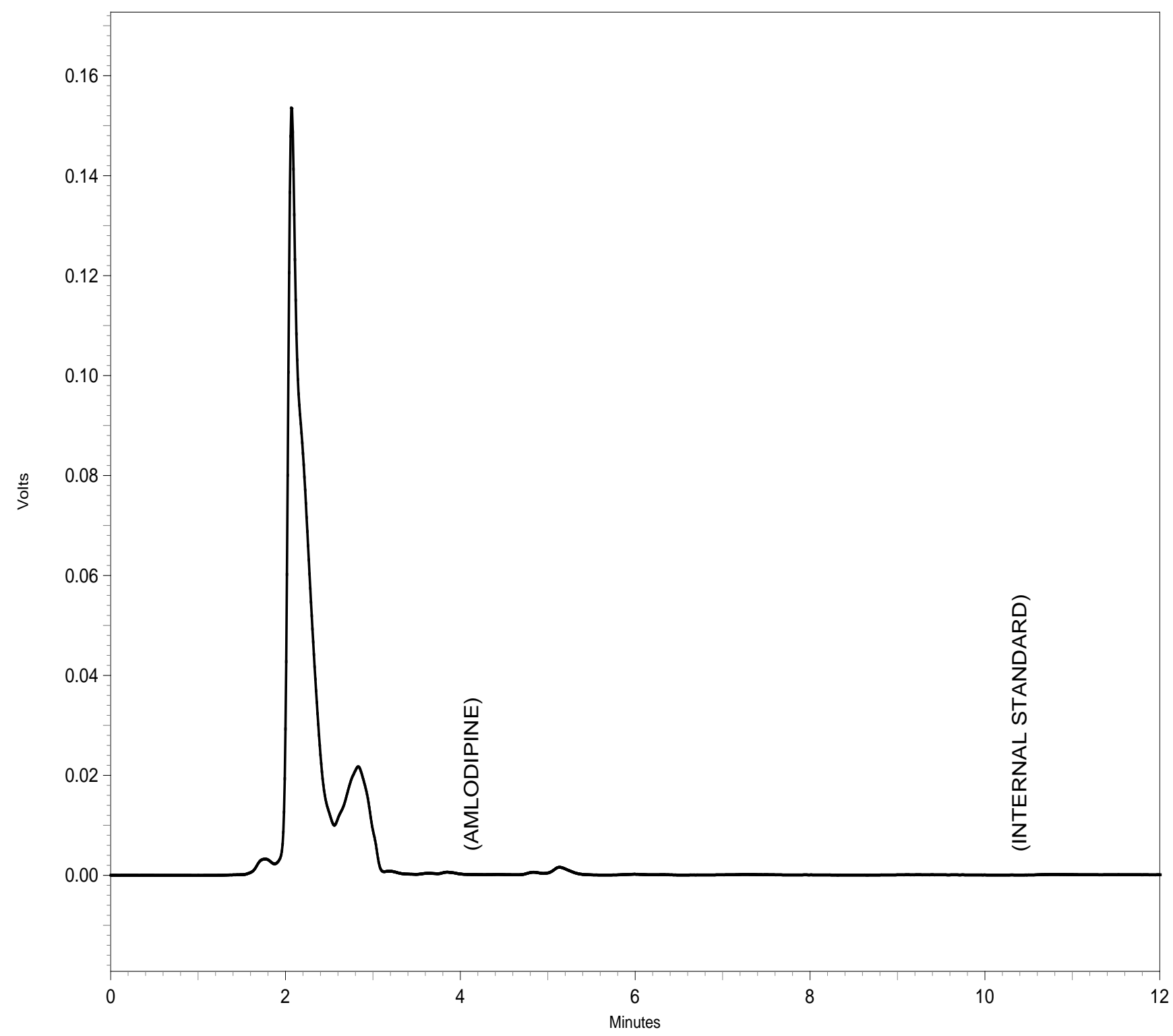

Fig. (2). Blank plasma chromatogram. 
der the proposed assay condition internal standard and amlodipine had a retention time of 4.12 and $8.31 \mathrm{~min}$, respectively, rest of the peaks were due to the plasma components. Amlodipine and internal standard were very well resolved under the proposed chromatographic conditions. None of the drug free plasma samples studied in this assay yield endogenous interference at these retention times (Fig. 2).

\section{Accuracy}

The mean percent accuracy of the proposed method was found to be $97.65 \pm 5.89 \%$.

\section{Precision}

Intra day precision for amlodipine was $0.97 \pm 0.09,8.91$ \pm 0.30 and $47.27 \pm 1.38$ for the spiked concentration at 1.0, 10 and $50.0 \mathrm{ng} / \mathrm{mL}$ and the percent coefficient of variation $(\% \mathrm{CV})$ was $9.77,3.41$ and 2.93 , respectively. Inter day precision for amlodipine was $0.98 \pm 0.09,10.7 \pm 0.72$ and 49.82 \pm 2.22 for the spiked concentration at 1.0, 10.0 and 50.0 $\mathrm{ng} / \mathrm{ml}$ and the percent coefficient of variation $(\% \mathrm{CV})$ was $9.24,6.73$ and 4.47 respectively (Table $\mathbf{1}$ ).

\section{Linearity}

The linearity of each calibration curve was determined by plotting the peak area ratio of amlodipine to internal standard versus nominal concentration of amlodipine. For linearity study seven different concentration of amlodipine were analyzed $(0.50,1.0,2.5,5.0,10.0,15.0,25.0$ and $50.0 \mathrm{ng} / \mathrm{mL})$. The peak area response was linear over the concentration range studied. Each experiment at all concentration was repeated three times on three separate days to obtain the calibration data. The coefficient of correlation $\mathrm{r}^{2}$ was found to be 0.9996. The limit of quantification and limit of detection were 0.1 and $0.250 \mathrm{ng} / \mathrm{mL}$, respectively.

\section{Recovery}

The mean extraction recoveries of amlodipine determined over the concentration of $1.0,10.0$ and $50.0 \mathrm{ng} / \mathrm{ml}$ were $97.60 \pm 3.56,96.85 \pm 1.92$ and $98.53 \pm 0.67 \%$. For the internal standard $(200 \mathrm{ng} / \mathrm{ml})$, the mean extraction recovery was $97.66 \pm 0.84 \%$ (Table 1).

\section{Stability Study}

Short-term and long-term stock solution stability study was evaluated, which proved no significant deviation from normal value when stored at $4^{\circ} \mathrm{C}$. The stability of amlodipine in plasma was determined by measuring concentration change in quality control samples over time. Stability was tested by subjecting the quality controls to three freeze-thaw cycles and compared with freshly prepared quality control samples. As shown in Table 2, the mean concentration of amlodipine in quality control samples did not change significantly within the time period under the indicated storage conditions. Long-term stability studies results conclude that amlodipine is stable in plasma matrix at least for 30 days when stored at $-20^{\circ} \mathrm{C}$.

\section{System Suitability}

System suitability test was performed daily before the run of analytical batch to check detector response to the analyte. Both the formulations were well tolerated by all the volunteers in both the phases of study. No clinical adverse events occurred during the study. The mean concentrationtime profile for the two brands of amlodipine $5.0 \mathrm{mg}$ tablets is shown in Fig. (3). All calculated pharmacokinetic parameter values were in good agreement with the previously reported values. For bioequivalence evaluation, $\mathrm{AUC}_{0-t}$, $\mathrm{AUC}_{0-\infty}$ and $C_{\max }$ were considered as primary parameters. The mean and standard deviation of these parameters of the two formulations were found to be very close, indicating that the plasma profiles generated by test formulation is comparable to those produce by reference formulation. Analysis of variance (ANOVA), after log transformation of the data, showed no statistically significant $(p>0.05)$ difference between the two formulations. The results of pharmacokinetic parameters are presented in Table $\mathbf{3}$.

\section{CONCLUSION}

An HPLC-UV based method has been developed for quantification of amlodipine in human plasma. The sensitivity and simplicity of the method makes it suitable for pharmacokinetic studies. The statistical comparison of $\mathrm{AUC}$ and $\mathrm{C}_{\max }$ clearly indicated no significant difference in the two formulations of $5.0 \mathrm{mg}$ of amlodipine tablets. Ninety percent confidence interval for the mean (T/R) of $\mathrm{AUC}_{0-t}, \mathrm{AUC}_{0-\infty}$ and $\mathrm{C}_{\max }$ indicates that the reported values were entirely within the bioequivalence acceptance range of $80-125 \%$ (using log transformed data). Based on these results a concise decision on bioequivalence was taken. Hence it was concluded that formulation 'Test' is bioequivalent with formulation 'Reference' and can be interchangeable in clinical practice.

Table 1. Precision Studies of Amlodipine (ng/mL)

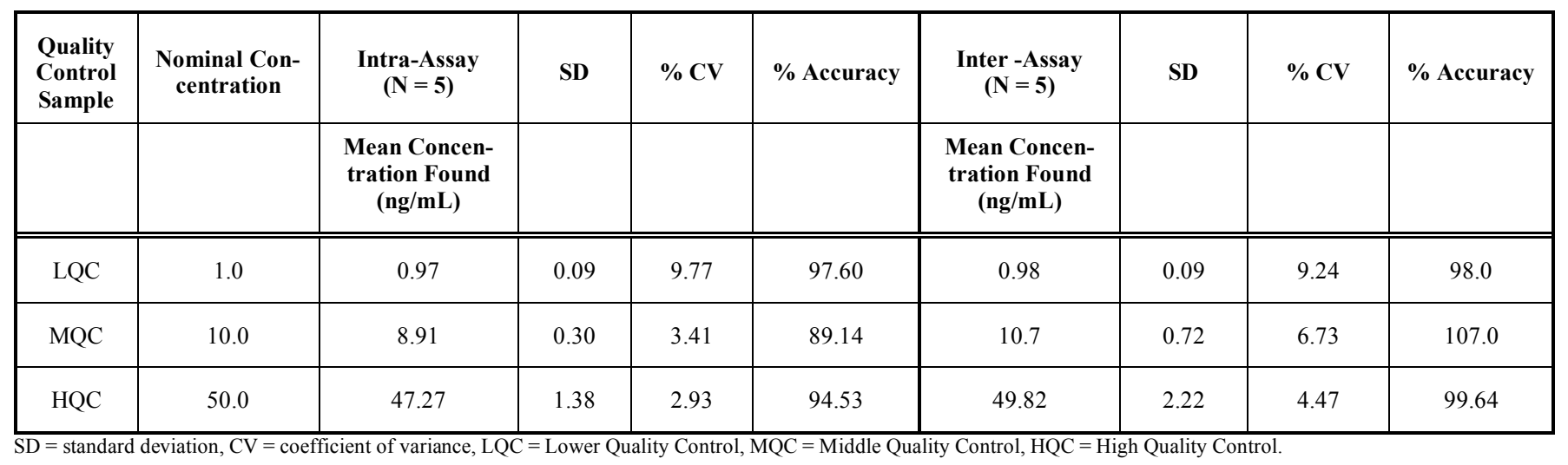


Table 2. Stability of Human Plasma Samples of Amlodipine

\begin{tabular}{|c|c|c|}
\hline Sample Concentration $(\mathrm{ng} / \mathrm{mL})(\mathrm{n}=6)$ & Concentration Found $($ Mean \pm S.D. $)(\mathrm{ng} / \mathrm{mL})$ & $\% \mathrm{CV}$ \\
\hline \multicolumn{3}{|l|}{ Short-term stability $(1,2,3$ h) } \\
\hline 10.0 & $10.62 \pm 0.92$ & 8.72 \\
\hline 50.0 & $49.43 \pm 0.86$ & 1.75 \\
\hline 1.0 & $0.94 \pm 0.06$ & 6.64 \\
\hline 10.0 & $13.56 \pm 1.28$ & 9.45 \\
\hline 50.0 & $47.79 \pm 4.08$ & 8.55 \\
\hline 50.0 & $50.93 \pm 0.14$ & 0.28 \\
\hline \multicolumn{3}{|l|}{ Freeze thaw Stability (3 Cycle) } \\
\hline 1.0 & $1.07 \pm 0.09$ & 8.92 \\
\hline 10.0 & $10.54 \pm 0.81$ & 7.73 \\
\hline 50.0 & $49.86 \pm 2.08$ & 4.18 \\
\hline
\end{tabular}

MEAN CONCENTRATION - TIME CURVE FOR 24 VOLUNTEERS (REFERENCE AND TEST PRODUCT)

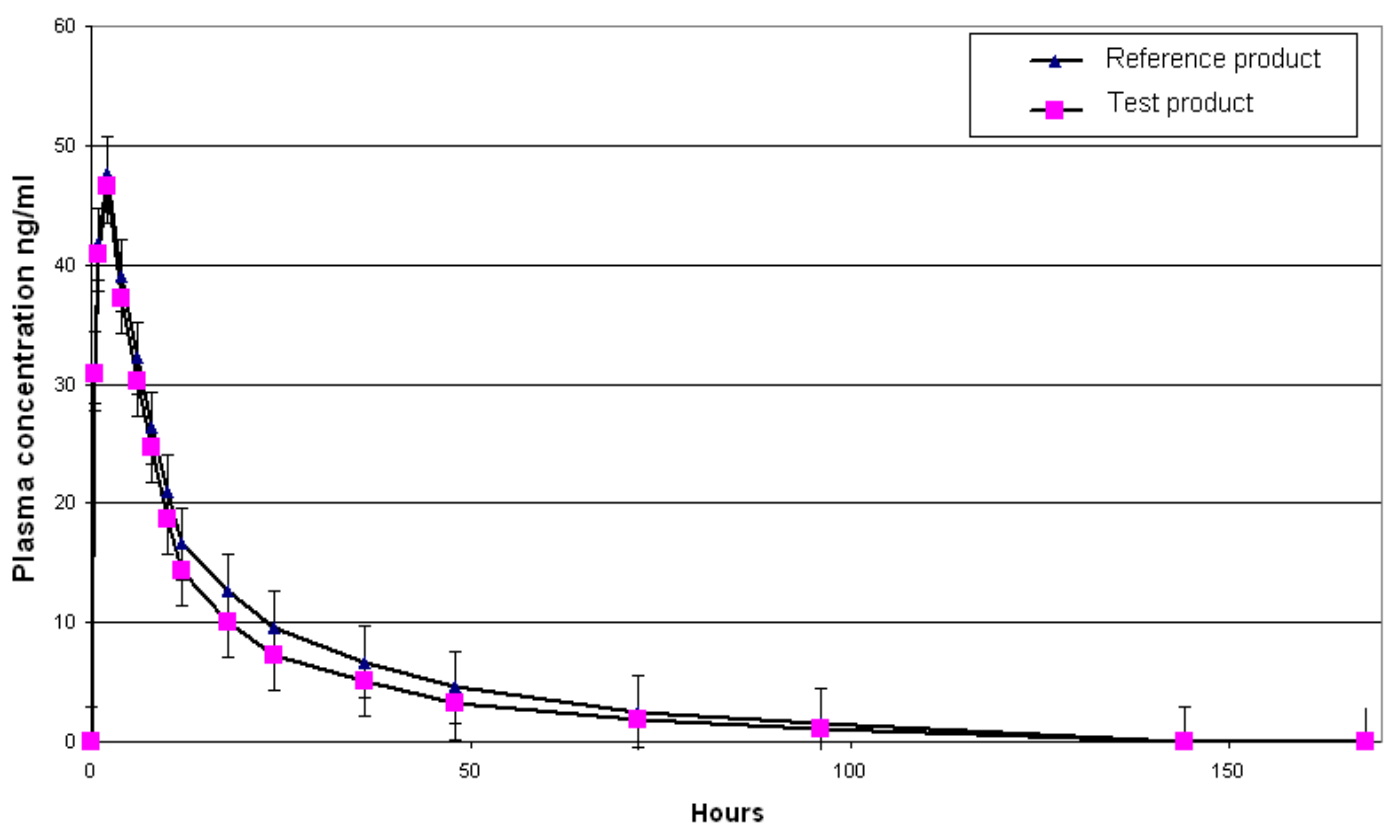

Fig. (3). Mean concentration - Time curve for 24 volunters (reference and test product). 
Table 3. Pharmacokinetic Parameters

\begin{tabular}{|c|c|c|}
\hline Pharmacokinetic Parameters & Reference & Test \\
\hline \hline $\mathrm{C}_{\max }(\mathrm{ng} / \mathrm{ml})$ & $791.5 \pm 13.7$ & $60436.4 \pm 9714.9$ \\
\hline $\mathrm{AUC}_{0-24}(\mathrm{ng} / \mathrm{ml})$ & $56004.1 \pm 12549.4$ & $72443.5 \pm 12820.8$ \\
\hline $\mathrm{AUC}_{0-\infty}(\mathrm{ng} \mathrm{h} / \mathrm{mL})$ & $67160.6 \pm 15049.5$ & $0.007 \pm 0.001$ \\
\hline $\mathrm{K}_{\mathrm{el}}$ & $0.007 \pm 0.001$ & $2359.4 \pm 10.0$ \\
\hline Half life & $2331.1 \pm 8.2$ & \\
\hline
\end{tabular}

\section{REFERENCES}

[1] Ma, Y.; Qin, F.; Sun, X.; Lu, X.; Li, F. J. Pharm. Biomed. Anal., 2007, 43, 1540.

[2] Mohammadi, A.; Rezanour, N.; Dogaheh, A.M.; Bidkorbeh, G.F.; Hashem, M.; Walker, R.B. J. Chromatogr. B., 2007, 846, 215.

[3] Park, J.Y.; Kim, K.A.; Park, P.W.; Lee, O.J.; Ryu, J.H.; Lee, G.H.; Ha, M.C.; Kim, J.S.; Kang, S.W.; Lee, K.R. Clin. Therapeut., 2006, 28,837 .

[4] Suchanova, B.; Sispera, L.; Wsol, V. Anal. Chim. Acta, 2006, 573, 273.

[5] Zarghi, A.; Foroutan, S.M.; Shafaati, A; Khoddam, A. Farmaco., 2007, 60, 789 .

[6] Naidu, K.R.; Kale, U.N.; Shingare. M.S. J. Pharm. Biomed. Anal., 2005, 39,147 .
[7] Streel, B.; Laine, C.; Zimmer, C.; Sibenaler, R.; Ceccato, A. $J$ Biochem. Biophys. Methods, 2002, 54, 357.

[8] Guidance for Industry. Bioanalytical method validation. US department of health and human services. Food and drug administration, Center for Drug Evaluation and Research, CDER, Rockville, Maryland, 2001.

[9] Guidance for Industry. Statistical approaches in establishing bioe quivalence. US department of health and human services. Food and drug administration, Center for Drug Evaluation and Research, CDER, Rockville, Maryland, 2001.

[10] Bolton, S. Experimental design in clinical trail in: pharmaceutical statistics practical and clinical applications, Marcel Dekker: New York, 1984, Vol. 80, pp. 384-443.

(C) Meyyanathan et al.; Licensee Bentham Open.

This is an open access article distributed under the terms of the Creative Commons Attribution License (http://creativecommons.org/licenses/by/2.5/), which permits unrestrictive use, distribution, and reproduction in any medium, provided the original work is properly cited. 